\title{
A Paisagem Percebida por um Sistema Complexo
}

\section{The Landscape Perceived by a Complex System}

\author{
Rodrigo Dutra Gomes ${ }^{1 *} \measuredangle$ iD, Jeferson Emanuel de Lemos ${ }^{2} \bowtie$ iD \\ 1*Programa de Pós-Graduação em Geografia, Departamento de Ciências Geográficas, \\ Universidade Federal de Pernambuco - Recife, Pernambuco, Brasil. \\ 2 Programa de Pós-graduação em Geografia, Departamento de Geocências, Universidade \\ Federal da Paraíba - João Pessoas, Paraíba, Brasil \\ E-mail: jefersonlemos88@gmail.com (JEL). \\ E-mail para correspondência: rdutragomes@gmail.com (RDG).
}

Recebido (Received): 08/02/2019 Aceito (Accepted): 18/09/2019

\begin{abstract}
Resumo: O que é o sujeito que percebe a Paisagem? O que é a percepção, o conhecimento, realizado por este sujeito? Na cultura científica moderna o sujeito do conhecimento foi considerado um ser racional e equilibrado que poderia conhecer o mundo objetivamente, sem a influência das subjetividades individuais e sociais. A percepção da Paisagem na Geografia pela abordagem sistêmica carrega essa influência. A Teoria da Complexidade traz novas leituras sobre o sujeito e sua percepção, com repercussões sobre a percepção da Paisagem. Os argumentos se deram num viés biológico cibernético-funcional, apresentando a proposta da Biologia do Conhecer. Os contatos com a Paisagem se deram pelas congruências e divergências com leituras já realizadas pelos autores conhecidos. Pela Complexidade a ciência analítica deixa de ser um campo objetivo, não existindo um sujeito racional, e sim um sujeito bioantroposocial auto-reflexivo que buscar uma objetivação de suas práticas. O sujeito/observador é um sistema complexo e a Paisagem se torna ao mesmo tempo individual e social, pois não separa a ideologia do sujeito (que é socialmente construída) da sua individualidade autônoma - e isso em termos biológicos. A percepção da Paisagem se torna momentânea e efêmera,dependente das condições singulares de quem observa, no momento que observa; variando de acordo com as condições do organismo em sua relação com o ambiente - que também é variante. O sujeito como o organismo caracteriza-se por ser um processo em transformação, com a leitura da paisagem variando de acordo com essa ininterrupta transformação.
\end{abstract}

Palavras-chave: Percepção; Complexidade; Observador; Leituras Momentâneas; Efêmeras.

\begin{abstract}
What is the subject that perceives the Landscape? What is the perception, the knowledge, realized by this subject? In Western Culture the man (in moral terms), or subject (in terms of knowledge), was considered a rational and equilibrated being, whose essence differentied and transcended the physical matter. The Theory of Complexity comes new readings about the subject and his perception, with repercussions in the way of apprehending Landscape. It is intended to discuss the conception of the subject by Complexity, through the Theory of the Observer, and some repercussions on the perception of the Landscape. The arguments were based on a cybernetic-functional biological direction, presenting the proposal of Biology of the Knowledge. The contacts with the Landscape dialogue with autors that reflect the landscape, presenting congruences and divergences. By Complexity Theory the analytical science is not an objective field, but a field of knowledge dependent of the subject and defined by a methodology. In this way, there is no rational subject capable of knowing the objective reality. The subject / observer is a complex system and the perception of the Landscape becomes momentary and ephemeral. The subject as a organism is characterized by being a process in transformation, with the perception of the landscape change as this transformation.
\end{abstract}

Keywords: Perception; Complexity; Observer;Perception Momentary; Ephemeral. 


\section{Introdução}

Uma assertiva genérica: a construção do espaço geográfico se dá a partir da relação entre o homem e a natureza. Mas o que é esse homem que se relaciona com a natureza e constrói o espaço?

Com respeito à Paisagem, pode-se dizer que a Paisagem é o espaço percebido e apreendido pelo sujeito. Mesmo se referenciando no olhar, a Paisagem não é somente o que se vê, mas o que, nesta visada, se percebe com os sentidos. Mas o que é esse sujeito que percebe e apreende a Paisagem? O que é o olhar e a percepção, em termos amplos, o conhecimento, realizado por este sujeito?

$\mathrm{Na}$ ciência ocidental moderna o sujeito do conhecimento foi considerado um ser racional. Em sua proposta matricial em Descartes (1991) o sujeito era uma substância (ego cogitans) que se diferenciava e transcendia a matéria (res extensa). A partir das direções e regras oferecidas pela razão esse sujeito conseguiria conhecer o mundo objetivamente (como ele é em si), de forma imparcial e independente das subjetividades vacilantes. Presentes desde as discussões dos racionalistas e empiristas nos séculos XVII e XVIII, a reflexão sobre a objetividade e presença das subjetividades no conhecimento foi guiada na Ciência experimental no século XIX predominantemente pelo positivismo e século XX pelo neopositivismo. Na Geografia pós-Segunda Guerra, principalmente a partir dos países anglo-saxões, a objetividade se firmou como uma das principais direções de inquérito na Geografia. A Teoria dos Sistemas é uma das principais teorias utilizadas pela Geografia desde a década de 50 e carregam essa influência, com a sua aplicação trazendo a premissa de se objetivar a prática.

Contudo, esta figura de sujeito racional, e capaz de conhecer objetividade a realidade, está sendo questionada pelos próprios desenvolvimentos científicos que orientou. Para examinar esse sujeito estão as discussões em torno da Teoria do Observador, que tem o embasamento dos Sistemas Complexos como suporte. Sob o pilar sistêmico-cibernético, a partir de noções como recursão e auto-organização e suas repercussões na biologia, se estruturou a Biologia do Conhecer pelos trabalhos de Maturana e Varela (2001). Os argumentos desta proposta serão utilizados para discutir a leitura bio-sistêmica-cibernética do sujeito chamado aqui de Sujeito Sistêmico - bem como algumas repercussões possíveis para a percepção da Paisagem. A reflexão buscará utilizar-se do argumento biológico, sem que para isso se caia em reducionismos extremos e monismos metodológicos; mas ao contrário, buscando desvelar os multidomínios e dimensões não redutíveis deste sujeito.

Pretende-se, então, discorrer sobre esta figura de sujeito trazida pelo contexto da Complexidade, via Teoria do Observador, com algumas repercussões já observáveis sobre a percepção da Paisagem. Os argumentos se deram num viés biológico sistêmico-funcional, apresentando a proposta da Biologia do Conhecer. Os contatos com a Paisagem se deram em diálogos com autores conhecidos - como G. Bertrand (2002) -, demonstrando congruências e divergências dos argumentos da Teoria do Observador com as leituras já realizadas sobre a paisagem por outros autores e perspectivas. Para contextualizar a Teoria do Observador na Geografia foram expostas reflexões já realizadas com esta teoria sobre a construção do espaço geográfico. Uma das repercussões desta perspectiva é o questionamento da objetividade científica tornandose a Ciência sujeito-dependente, ou seja, inseparável da subjetividade individual e social do pesquisador. Buscou-se então, em seguida, desenvolver a ideia de Paisagem como sujeito-dependente, trazendo leituras não típicas para a perspectiva lógico-formal de estudar o espaço.

\section{O Sujeito pelo Sistêmico: O Homem como um Sistema Complexo.}

O biólogo H. Atlan (1978) defende que a noção de sujeito ocidental está sendo reinterpretado pelo viés das máquinas cibernéticas biológicas. No caso, trata-se de uma nova representação pelo arcabouço teórico dos sistemas complexos, tanto em seu sentido existencial (ontológico), quanto do conhecimento (epistemológico). Esta é a direção que o sujeito será aqui tratado, como um sistema físico, biológico e social, produtor de cultura - e não um ser racional cuja essência se diferencia da natureza, mas ao contrário, assim como a natureza, o sujeito é múltiplo em manifestação. Esta direção pretende chegar na concepção de sujeito de Morin (1991), sendo este sujeito, há um só tempo, físico, biológico, psíquico, cultural, social, histórico. Esta leitura do Sujeito tem como base as discussões em torno da Teoria do Observador, que se refere à definição das condições de possibilidade e fundamentos de uma 'teoria da descrição' e de uma 'teoria da cognição', sobre como conhecemos o mundo enquanto entidades físicas. Tal proposta se deu a partir do viés sistêmico-cibernético e teve como importantes protagonistas Henri Von Foerster, Humberto Matura e Francisco Varela (BÉJIN, 1978, p.126). Tomou-se aqui as considerações dos chilenos H. Maturana e F. Varela, biólogos pertencentes à perspectiva sistêmica da Cibernética de Segunda Ordem, que desenvolveram a chamada Biologia do Conhecer.

Inicialmente Foerster (1984) ao descrever teoricamente sistemas cibernéticos de segunda-ordem, chamados de morfogenéticos (que auto-produzem sua própria forma), deparou-se com um problema epistemológico: os próprios pesquisadores (inclusive ele mesmo) eram as máquinas cibernéticas que estavam 
sendo formalmente descritas. Ao relevar isso o autor percebeu que um sistema de relações se formava entre o sujeitos-pesquisadores (sistemas cibernéticos morfogenéticos) e o objeto externo percebido, com esta relação sujeito-objeto também devendo ser objeto de observação e investigação. Foerster (1984) declarou a necessidade da própria cibernética se auto-objetivar. Reconheceu, nesta situação, a impossibilidade de se separar o observador (sujeito) e o observado (objeto) - na mesma direção destacada pela mecânica quântica no início do século XX (HEISENBERG, 1981). Dentro do ramo científico experimental, foi a segunda vez que uma ciência efetivamente reconheceu a necessidade de auto-objetivar suas posturas nos próprios procedimentos de pesquisa - do observador se observar observando. Houve assim, a necessidade de se pensar uma teoria de quem observa, uma teoria do observador - e sendo os observadores sistemas biológicos foram os biólogos que fizeram tal teoria (HEYLIGHEN; JOSLYN, 2001).

Sob estas influências Maturana e Varela (2001) partem das questões: o que é a vida? O que é próprio dos sistemas vivos desde a sua origem, e que permanece invariante durante as sucessivas gerações? Ou em termos de máquinas cibernéticas, que tipo de máquina é o ser vivo? Maturana e Varela (2001) recorrem aos mecanismos homeostáticos que Claude Shannon (precursor da Teoria da Informação) havia refinado. Os seres vivos seriam então, um tipo particular de máquina homeostática que conseguiria manter alguns de seus parâmetros imóveis ou flexíveis no interior de um intervalo restrito de valores, mantendo estabilidade e coerência interna no sistema. O termo máquina é empregado aqui no sentido de seu funcionamento, e não da natureza, ou materialidade de seus constituintes. Essa associação não é nova, remetendo à descrição mecanicista de Descartes (2009) no XVII e materialista de La Mettrie (1981) no XVIII - sendo o homem, para este último, uma máquina que produziria suas próprias partes. A Teoria do Observador oferece uma releitura científica contemporânea desta analogia, agora em bases sistêmicas-biológicas, em termos de máquinas cibernéticas. Com base na ideia de auto-organização, afirmado na cibernética por Foerster (1984), para Maturana e Varela (2001) essas máquinas desenvolveriam o processo de autopoiese, utilizado por eles para denominar a autoprodução dos seres vivos - com o poiese dando um sentido de 'criação' para o processo de produção. Referenciados em princípios recursivos apresentam os seres vivos como as únicas máquinas na natureza que conseguem produzirem-se a si próprios; e isso sem fazer qualquer distinção de reino ou espécies (da bactéria ao homo sapiens).

Pela autopoiese na dinâmica viva uma rede de produção de componentes se estabelece, de forma que, estes próprios componentes criam o sistema circular que os produz, numa relação de congruência entre si próprios e o ambiente. A relação com o ambiente se dá pelo 'acoplamento estrutural', com a relação entre o sistema vivo e o ambiente sendo, ao tempo, de autonomia e dependência. Neste acoplamento ocorrem influências mútuas entre o ser vivo e o ambiente, com o ambiente produzindo mudanças na estrutura do sistema, que, por sua vez, ao retroagir com o ambiente o altera.

Os seres vivos são considerados como 'fechados operacionalmente', no sentido que sua autonomia decorre do funcionamento do sistema sobre si mesmo, de forma que, em termos de sistemas individuais, os seus processos somente ocorrem nos limites do sistema e em dependência de sua estrutura e organização. Isso não quer dizer, obviamente, que o ser vivo é um sistema fechado a troca de matéria e energia. Esse 'fechamento' é sobre sua operacionalidade e caracteriza-se basicamente por apresentar processos dependentes recursivamente uns dos outros pela geração e realização desses mesmos processos. Em termos de experiência individual isso quer dizer, que, no âmbito do ser vivo, cada unidade viva, detém um vivência única e própria do mundo. Mingers (1995) sugere que tais considerações se assemelham ao proposto por E. Husserl no campo da fenomenologia que enfatiza a inevitabilidade do sujeito ser constrangido a experiênciar o seu próprio mundo, individual e experiencial, e que nunca poderá ser comparado objetivamente com o mundo de outro sujeito.

Fisicamente esse sistema circular operacionalmente fechado se dá a partir de balanços termodinâmicos e processamento de informação, trazendo consigo, além das ordenações e redundâncias, as desordens e os ruídos (típicos dos sistemas complexos) que são fomentadores de novos estados e processos criativos dos seres (por ex. as mutações em Darwin, a criatividade humana etc). Caso esse processo circular seja interrompido, ou cessado, a unidade autopoiética caminhará à entropia máxima, em forma de equilíbrio termodinâmico e morte de sua organização - com uma final desintegração no ambiente (RAMOS, 2005).

A história de mudanças estruturais de uma unidade, sem que haja a perda de sua organização é denominado de 'ontogenia', com a 'deriva estrutural' sendo o caminhar da unidade no ambiente em seu acoplamento estrutural. Fechados operacionalmente ao longo de sua deriva estrutural, os sistemas vivos são considerados como determinados estruturalmente. Isso quer dizer que tudo o que ocorre com o ser vivo a todo instante no ambiente é dependente de sua estrutura naquele instante. Isso também não significa dizer que sejam prédeterminados ou condicionados em relação ao ambiente, mas antes, que são dependentes de sua história (ontogenia) de mudanças estruturais (deriva estrutural). Essa determinação em relação a si mesmo é o que levou os autores a formularem a máxima de que "tudo o que é dito é dito por um observador".

Como repercussão, Maturana (1997) coloca como imaginária o problema de se considerar a "coisa em si” (a 
realidade independente do observador) - o que para a observação da Paisagem sugere considerar os objetos e processos observados como uma "coisa em si". Sobre isso, para o autor, somente cabe ao sujeito imaginar um mundo existindo independente dele mesmo. A certeza de uma realidade externa ao sujeito é imediata apenas pelo costume cotidiano, de, no viver, se conceber o mundo como algo em si, independente do juízo das pessoas. Isso remete ao que Nietzsche (2005) chamou de "fé na gramática", sobre a tendência de se confundir os significados das coisas com as coisas em si, ou seja, de se aceitar os conceitos como se significassem exatamente o objeto representado, buscando afirmar uma universalidade que na verdade é abstrata, mas que, mesmo assim, se julga intrínseca ao ato de representar. Em Maturana e Varela (2001) as representações e significados criados pelo sujeito-observador não são independente da circunstância na qual se encontra na relação com o meio e consigo mesmo, com suas representações ficando condicionadas pela sua determinação estrutural. Não é possível assim, inferir uma existência independente daquilo que estes observadores fazem, como se os objetos e processos fossem entes em si mesmo - e isso nem mesmo sequer o próprio observador que a si se aponta. A objetividade de um mundo existindo como independente dos observadores é usada para observá-lo devido ao costume da tradição científica a conceber o mundo como independente de quem observa (GRACIANO, 1997). Pela leitura biológica de Maturana (1997) as representações da realidade são dependentes da história e circunstância do organismo do observador no instante da apreensão do objeto. Assim, apenas para exemplificar, a própria concepção de ser vivo que está sendo aqui descrita também passa por esse filtro, ou seja, a própria concepção cibernética de sistemas autômatos que Maturana e Varela (2001) carregam é uma representação detendo vantagens e limites para se estudar o ser vivo - num processo de auto-objetivação (conforme esclarecido pela Cibernética de Segunda Ordem - com o observador se observar observando).

Para os geógrafos ainda presos à crítica ao determinismo ambiental presentes no início do século XX, é importante novamente frisar que, por esta perspectiva, o ambiente não se apresenta como agente de determinação das atitudes do organismo, mas sim, como um agente de perturbação, que apenas desencadeará diferentes estados de funcionamento nele, decorrendo então nas atitudes dos organismos vistos como uma adaptação e resposta às perturbações ocorridas. A vivência dessas perturbações advindas do ambiente externo são vividas internamente pelo ser vivo de acordo com suas "capacidades" naquele instante, que desencadeará um ou outro estado de funcionamento no organismo - e daí uma ou outra atitude. As perturbações externas determinam, assim, apenas as circunstâncias históricas em relação à ocorrência desses estados, mas não em relação à determinação dos mesmos, cuja resposta será dada de acordo com as condições do organismo no instante da perturbação (MATURANA, 1978, p.151). Em termos de acoplamento estrutural os seres humanos e o ambiente interagem, com autonomias e dependências, de maneira que ambos vão mudando ao longo de suas derivas.

Em organismos metacelulares, que se referem a entidades autopoiéticas de $2^{\mathrm{a}}$ ordem, por constituir-se de grupos de células, há o desenvolvimento da formação do sistema nervoso, que, no caso do homo sapiens, atingiu a maior complexidade conhecida entre os seres vivos, oferecendo uma robusta estrutura que potencializou sua capacidade neural e o dotou de características como o julgamento, a estética, o raciocínio e capacidade de discernimento. Essa estrutura nervosa habilita o pensamento e ações conscientes diante dos estímulos ambientais, e que ao favorecer a relação do ser vivo com o ambiente permite a emergência do humano em sua constituição individual e social - sendo este o alicerce para toda uma complexidade de domínios e escalas que não se reduz ao fenômeno e argumento biológico (MATURANA; VARELA, 2001, p.110).

O sistema nervoso é também considerado como fechado operacionalmente, aberto à matéria e energia, mais fechado para informações. Neste sentido, pode-se dizer que o sistema não "recebe informação", mas sim, computa os estímulos fornecidos pelo ambiente, com o resultado de suas operações sendo suas próprias operações. Essa computação é, portanto, realizada no interior das fronteiras do próprio sistema, sem que haja qualquer 'troca' de informação com o exterior, ocorrendo, na verdade, um processamento interno a partir das inter-relações e configurações 'fechadas' ocorridas entre as células nervosas. Esses estímulos só se tornarão "informação" após todo o processamento interno biológico-neural. O sentido da informação se torna uma emergência (o todo é maior que a soma das suas partes - BERTALANFFY, 1973) enquanto significado atribuído pelo sujeito; ou seja, com a informação e o seu significado sendo justamente uma emergência (uma totalidade) que só pode ser concebida ao final de todo um processo que envolve vários elementos e etapas, detendo ela uma propriedade diferente da dos elementos e etapas que deram alicerce. Em concordância com a Teoria da Informação de Shannon e Weaver, para que haja a ocorrência de informações são necessários pelo menos cinco elementos organizados linearmente: (1) uma fonte de informação, (2) um transmissor, (3) um canal de transmissão, (4) um receptor e (5) um destino- ou seja, a informação somente surge à nível de totalidade pela relação destes elementos (LUZZI; VASCONCELLOS, 1999).

O sistema nervoso se intercepta com o organismo nas suas superfícies sensoriais (receptora dos estímulos externos), e efetoras (responsáveis pela redundância dos estados internos ao sistema). Nessa interação, os sensores e efetores constituem as superfícies de encontro do sistema com um ambiente, que somente será 
definido pelo organismo de acordo com o estado de sua organização naquele instante. Enquanto componentes do sistema nervoso, tais superfícies não representam pontos de entrada ou saída de informação, mas apenas células neurais que se interconectam com outras células neurais, cuja mudança de estado de atividade é desencadeada pelas mudanças de estado destas mesmas células com as quais estão interconectadas; com as superfícies sensoriais e efetoras ocasionando os estímulos nestas células neurais. O sistema nervoso constituise, assim, como um sistema fechado que funciona de maneira contingente (cega) e que modula o curso das interações do organismo no ambiente. Em termos neurais a conduta, ou comportamento, torna-se uma emergência do dinamismo fisiológico e é, nesta perspectiva, resultado da congruência da dinâmica de funcionamento do sistema nervoso com as circunstâncias da vida do organismo no ambiente, resultado de sua história de mudanças estruturais no meio ao qual mantém a sua organização e adaptação (MATURANA, 1997).

Um dos aspectos marcantes da Teoria do Observador refere-se justamente à distinção dos domínios existenciais que podem ser discernidos no sistema vivo: o fisiológico-funcional, o comportamental-histórico, e o sócio-cultural. Sobre o fisiológico e comportamental, tal distinção é observada nas descrições cibernéticas desde a máquina de Turing (de Alan Turing). Considerada o primeiro modelo básico de 'máquina de conhecer' (o ser vivo) houve nela o reconhecimento de dois domínios funcionais que não poderiam ser reduzidos um ao outro: o mecânico, de processamento das informações de uma fita binária, e o comportamental global, que era o resultado expresso na tela da máquina (DUPUY, 1996). Agora, numa perspectiva biológica tal distinção ganha caráter ontológico referente aos domínios, ou, esferas de ações de existência, que podem ser discernidos nos seres vivos: fisiologia (mecânico-causal referente ao objeto cartesiano) e conduta (intencional-volitivo referente ao sujeito cartesiano). Na Biologia esta distinção é a ligada entre as abordagens funcionais-mecanicistas e abordagens históricas-evolucionistas (MAYR, 2008).

Reconhece-se que todo ser vivo existe basicamente em dois domínios biológicos que não podem ser confundidos um com o outro, em vista de não serem explicáveis em termos um do outro (mesmo se relacionando), com cada um devendo ser entendido em seu próprio âmbito de legitimidade. A fisiologia, enquanto estrutura interna, funciona como uma rede fechada e centrada em si, mudando, tanto internamente, quanto com o curso de suas mudanças no meio, de forma contingente no curso de sua própria atividade. A 'conduta' pode ser associada ao domínio de existência dos fenômenos psíquico, mental ou espiritual, podendo ser associado ao sujeito cartesiano.

Os domínios da fisiologia e da conduta são considerados como disjuntos, não se intersectando, de forma que, os processos de um não ocorrem no outro, embora, detenham uma relação de geratividade mútua, ou seja, uma relação geradora entre si. O domínio da conduta surge, então, como resultado da dinâmica fisiológica que dá origem ao organismo enquanto totalidade; e a conduta, por sua vez, como totalidade, ocorre nas interações do organismo com o ambiente, modulando e guiando a fisiologia que lhe dá origem. Tais domínios, na verdade, se modulam reciprocamente em um entrelaçamento de processos recursivos em sequências não-lineares. Cada um destes domínios é, assim, concreto e interconectado em seu operar, mas abstratos, um com relação ao outro, podendo ser separados somente em suas descrições (GRACIANO, 1997, p.56-84, MATURANA, 1997, p.109113).

Quando as unidades autopoiéticas se inter-relacionam, produz-se um novo domínio autopoiético definido como de $3^{\mathrm{a}}$ Ordem, caracterizando o fenômeno social. Os componentes desse meio ficam subordinados à manutenção da autopoiese de ordem superior. Na sua dinâmica, cada sociedade distingue-se das outras de acordo com as características das redes de interações que se realizam no seu interior. Por outro lado, por ser composto por seres vivos, todos e cada um integram e dinamizam o meio social a que pertencem, constituindo e influenciando o seu operar. Não existem, então, componentes supérfluos; caso um componente se perca, o sistema social muda, da mesma forma, que se a estrutura de um desses componentes mudar, por conta de sua deriva estrutural, o sistema social que este integra e gera também muda. Para ser membro de um grupo social o organismo deve seguir a conduta que o definem como tal, que em sociedades complexas, como nos primatas e humanos, envolve, dentre outros, mecanismos de submissão, cooperação e contestação, envolvimento emocional e construção de identidade social. Considerando que a dinâmica social é o meio pela qual o ser vivo se realiza como indivíduo, esta também funciona como seletora de mudanças estruturais, estabelecidos pelos próprios membros, a partir de suas condutas. Assim, toda sociedade é conservadora em sua organização, ou seja, das características dos componentes que a geram. De um lado, isso funciona como mecanismo de seleção e aceitação no processo de integração de novos membros externos na sociedade, e por outro lado, também não impede que os seus componentes interajam com outros sistemas sociais e constituam, a partir do conhecimento adquirido, uma rede de condutas diferentes que poderão influenciar a constituição da primeira.

Nesta perspectiva de congruências e abstrações entre os domínios existenciais, o conhecer biológico se torna uma ação efetiva operacional no domínio de existência do ser vivo, conectado de forma inerente ao seu autoproduzir-se a todo instante, levando à máxima: todo fazer é um conhecer e todo conhecer é um fazer (MATURANA; VARELA, 2001, p.35). Assim, no que se refere ao ser vivo, a ação de existir (ontológico) e ação de conhecer (epistemológico) reconhecem-se como inseparáveis no domínio de existência do organismo. 
Neste sentido, mesmo que servindo de discernimento, o conhecer e o existir são inseparáveis no processo de manutenção do ser vivo - podendo assim considerar o pensamento como uma ação efetiva do funcionamento do sistema nervoso do organismo homo sapiens.

Nas sociedades humanas, o mecanismo fundamental de interação social é a linguagem, sendo esta o meio pelo qual o Homo sapiens se realiza como Ser Humano ao produzir e reproduzir cultura e conhecimento, permitidos e potencializados pela sua estrutura biológica e cognitiva-neural - mas não fugindo à 'regra' do conhecer biológico fundamental. Não existe, assim, qualquer ser humano fora de um contexto social, constituído apenas na relação entre humanos, emergido e imerso na linguagem. Sobre tal perspectiva sistêmica recursiva, não é contraditório, portanto, afirmar que a "individualidade humana é social", com os indivíduos humanos somente se constituindo enquanto tais como seres sociais na linguagem - propondo uma leitura complementar entre a dualidade individuo/sociedade. A conduta de uma sociedade fica, assim, subordinada às mudanças de conduta de seus membros, já que ao realizar-se como indivíduo, a pessoa constitui e integra o ambiente social no qual vive (MATURANA, 1997, p.201).

Por esta perspectiva, as ciências e suas 'verdades', aceitas ou refutadas, ficam estabelecidas de maneira consensual entre os seus promotores; o que, por sua vez, gera concordâncias e também discordâncias. Neste movimento, consensos e dissensos são estabelecidos em grupos, que podem se dividir em coletivos, com cada um detendo seus consensos de verdades, o que, por sua vez, pode gerar dissensos e competição à nível de interação entre os grupos. A chamada objetividade referencia-se aqui no rigor dos parâmetros comumente estabelecidos em operações coordenadas que constituem o fazer científico, o que Maturana e Varela (2001) chamam de "objetividade entre parênteses". Tal sentido se assemelha à concepção de objetivação de Bachelard (1977) (apresentado melhor a baixo), onde o sujeito do conhecimento sabendo de suas limitações enquanto observador, buscar aplicar de maneira rigorosa, com base em sua carga cultural, um método, uma reflexão, um experimento etc. Tal consideração embasa e é embasada pela ideia de que o sujeito da pesquisa é reconhecido como ser biológico sem qualquer base de onipotência metodológica (monismo epistemológico), tornando-se o responsável pelas suas formulações e aceitação, ou não, por consensos e dissensos, de outros domínios cognitivos de percepção da realidade, ou ainda, outros conhecimentos e epistemologias: senso comum, filosofias, religião, artes etc.

\section{O Sujeito Sistêmico, o Espaço e a Paisagem: Aspectos Ontológicos e Epistemológicos}

De início, partimos do fundamento biológico de vivência do espaço e apreensão da paisagem. É importante lembrar que essa entrada biológica na Geografia, longe de ser algo novo ou estranho, é fundante na disciplina. O darwinismo e o evolucionismo foram influentes não só na Geografia em Ratzel, mas nos diversos conhecimentos que vinham se organizando na segunda metade do séc. XIX (STODDART, 1966). Não sendo aqui ingênuo em relação às perversidades geradas a partir da teoria eugênica, outras leituras a partir da filosofia, sociologia, economia, psicanálise etc utilizaram o sentido evolucionista e conflitual reafirmados pela teoria de Darwin (SCHALL, 2014). A teoria biológica, por exemplo, ofereceu argumentos para Nietzsche exclamar a condição animal do homem e declarar a primazia dos impulsos vitais sobre a razão. Em crítica à moral ocidental Nietzsche realçou a necessidade da revisão de todos os valores e certezas morais e científicas aceitas em Kant, preconizando a busca pelo super-homem. No Livro II da Gaia Ciência inicia:

Quer considere os homens com um olhar benevolente ou malevolente, vejo-os todos, e cada um em particular, fazer a mesma coisa: a saber, o que é útil para a sobrevivência da espécie. Ora, não é por amor a essa espécie que agem assim, mas simplesmente porque não há neles nada mais antigo, nada mais forte, mais inexorável, mais invencível que esse instinto - porque esse instinto é precisamente a essência de nossa espécie e de nosso rebanho (NIETZSCHE, 2006, p.37).

Em Nietzsche a dualidade cultura/biologia pode ser vista como algo superado, com o filósofo trazendo duas perspectivas para tratar o problema da "elevação do homem". Por um lado temos as relações biológicas de impulsos e de potência, onde determinada moral, cultura, filosofia pode ser vista como expressão de estados fisiológicos de um conjunto de impulsos. O homem e toda sua produção são considerados como resultantes de uma configuração de impulsos ou forças que também (mas não somente) tem pressupostos biológicos. A cultura e educação são vistos tanto pelo substrato biológico dos impulsos, quanto direcionando para um projeto educacional para a transformação radical do indivíduo (para o grande homem ou o seu fracasso). Para o autor os processos culturais são análogos aos biológicos. O ponto em comum dos dois processos está nos impulsos ou nas forças: igualmente ao organismo humano, a cultura é expressão de forças que lutam entre si por mais potência (FREZZATTI, 2004)

Para o campo de conhecimento geográfico a influência darwinista no final do século XIX tornou-se fecunda e claramente diversificada, oferecendo, no período, o arcabouço teórico para a constituição formal e 
disciplinar de uma Geografia institucionalmente firmada (MENDOZA et al. 1988, p.32). De acordo com Stoddart (1966, p.684) o paradigma darwinista trouxe para a Geografia uma influência duradoura, vinculado:

(1) a ideia de tempo como mudança, permitindo maiores elaborações para os estudos geológicos, geomorfológicos, pedológicos, climáticos, ecológicos etc, com influência também em áreas das ciências sociais;

(2) a noção de 'organização' ligada à de 'organismo vivo', ajudando a manter as ideias e interpretações acerca das 'regiões e estados' entendidos agora como 'macro-organismos', em substituição à visão teleológica vitalistas que detinham problemas de demonstração empírico-científica do élan vital;

(3) a ideia de luta e seleção natural, direcionando para questionamentos da relação homem/ambiente e dos efeitos deste ambiente sobre o homem. Essa discussão tem sido historicamente muito associada à sua vivência determinística, em autores aplicados na geografia humana e política como Ratzel e Semple, e em referência ao campo geomorfológico com W. Morris Davis (1850-1934) e sua evolução do relevo pelo Ciclo de Erosão;

(4) a ideia de aleatoriedade e mudança na dinâmica evolutiva dos organismos, inserindo um fator de probabilidade que obtinha respaldo pela expansão dos estudos estatísticos no período.

Tradicionalmente o fundamento biológico não é, assim, oposto à discussão das influências sociais e culturais nos indivíduos e em suas percepções. Por isso, não é estranho também que os argumentos de Santos (1988) sobre a Paisagem destaquem o alicerce corporal (e neste sentido biológico) da percepção da paisagem - servindo de analogia para a situação trazida pelo sistêmico:

A dimensão da paisagem é a dimensão da percepção, o que chega aos sentidos. Por isso, o aparelho cognitivo tem importância crucial nessa apreensão, pelo fato de que toda nossa educação, formal ou informal, é feita de forma seletiva, pessoas diferentes apresentam diversas versões do mesmo fato. Por exemplo, coisas que um arquiteto, um artista vêem, outros não podem ver ou o fazem de maneira distinta. Isso é válido, também, para profissionais com diferente formação e para o homem comum (SANTOS, 1988).

A partir de outros fundamentos os argumentos sistêmicos complexos detêm direções convergentes à de Santos (1988), mas adotando um viés biológico para embasar tais argumentos. Primeiramente serão realizadas considerações sobre a construção do espaço geográfico, sob a referência das dualidades típicas da Geografia para que, assim, se possa introduzir a relação entre Teoria do Observador e Geografia. Em seguida serão discorridas algumas repercussões na percepção e apreensão da Paisagem.

\subsection{A Construção do Espaço Geográfico}

Será aqui retomado algumas discussões sistêmicas em Gomes (2009) sobre a construção do espaço a partir de multidomínios e dimensões, com vista contextualizar as reflexões que serão realizadas sobre a Paisagem. É oportuno lembrar que estas distinções entre domínios existenciais destacados pela Teoria do Observador podem ser balizadas na distinção feita por Kirk (1977, p.317) (Figura 2) ao caracterizar a principal dicotomia na Geografia.

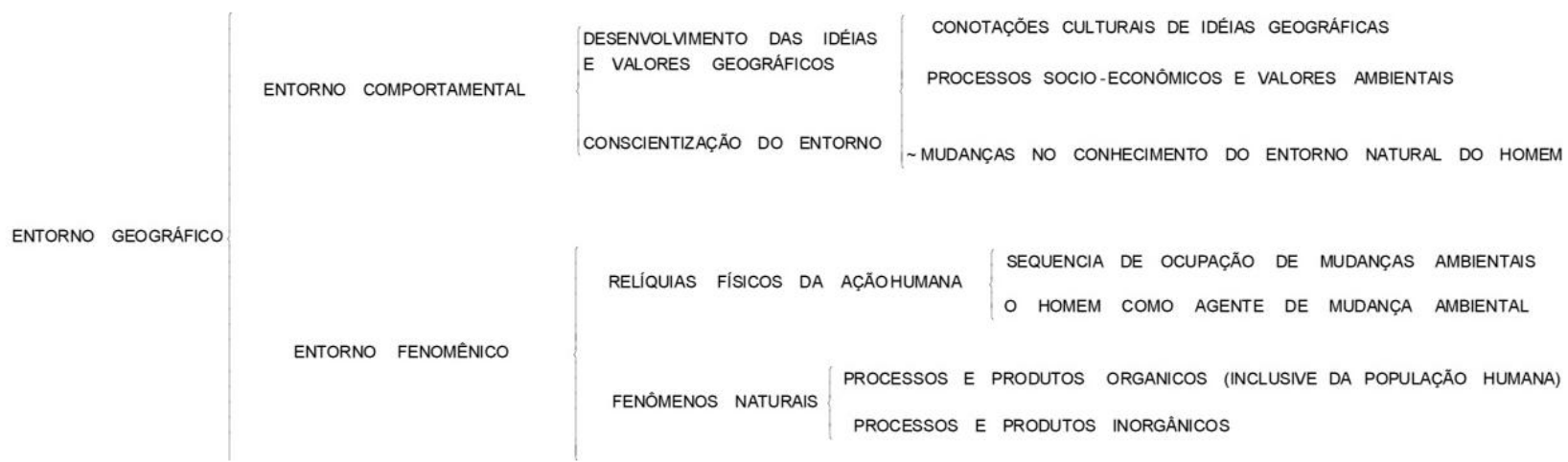

Figura 2: Dicotomia entre o entorno fenomênico material e entorno comportamental. Retirado de Kirk, (1977, p.316). 
A dualidade básica da geografia pode ser expressa em termos de, de um lado, o 'entorno fenomênico do objeto', abarcando as questões materiais da realidade, incluindo as obras do homem (sistemática, nomotético, sistêmico) e, por outro, o 'entorno comportamental' do sujeito, onde sua conduta sócio-cultural e sua "existência" são reconhecidas como exigindo procedimentos alternativos mais interpretativos para a investigação do assunto (funcionalismo, idiografia, regionalismo, humanismo etc). Inserido nos entendimentos sistêmicos expostos acima o espaço geográfico pode ser localizado como o produto espacial da vida humana na Terra. Assim, independente de suas diversas definições, pode-se sistemicamente dizer que a construção do espaço geográfico, no devir sócio-cultural humano no ambiente, se dá por meio de multi-domínios existenciais que se geram e modulam, mas não são redutíveis um ao outro, nem em manifestação, nem em entendimentos.

Outro aspecto marcante das derivações sistêmicas são as repercussões epistemológicas acerca da objetividade científica e que repercute diretamente na percepção da Paisagem. Vieram questionar e negar a possibilidade de se realizar um conhecimento científico, livre e ausente de quaisquer subjetividades, pautados em critérios absolutos e direcionado à obtenção de 'certezas' acerca do mundo. No movimento contrário de um monismo metodológico, ocorreu a necessidade de se considerar a influência da finitude e condição biológicasócio-cultural e emocional do conhecer do Sujeito, com a inconsistência e limitação de se aplicar e buscar uma única via de entendimento para o inquérito dos fenômenos. Na Geografia a subjetividade sempre foi presente na percepção da Paisagem (desde Humboldt (VITTE, 2010), esclarece-se aqui a leitura biológico-sistêmica disso - e não a contestação de que a percepção Paisagem aplicava uma objetividade pura, que nunca ocorreu. Longe de poder ser associado simplesmente a algum subjetivismo, tal perspectiva assume, na verdade, a presença do sujeito-pesquisador para a qualidade e rigor de suas elaborações. Desde o início das proposições da Cibernética de $2^{\mathrm{a}}$ ordem já havia se reconhecido de que a ciência tratava mesmo de 'modelos' simplificados, criados por um sujeito-máquina morfogenético processador de informações. As derivações que se seguiram corroboraram esta tese, afirmando mesmo a impossibilidade de se considerar qualquer conhecimento sem a presença de um observador que o pratique - entendimento antigo na Filosofia empirista, que foi preterido na ciência em nome da neutralidade pregada pelo princípio da objetividade, e que as leituras científicas-sistêmicas da Biologia do Conhecer traz contemporâneas revisões. Para a descrição desta consideração convém retornar a alguns dos entendimentos básicos que foram observados desde o modelo simplificado da máquina de Turing.

Nesta objetividade todas as leituras sobre a Paisagem, mas também sobre o território, região, geossistema etc, ganham um caráter de inerência no processo biológico, ou seja, o conhecer científico da realidade não se torna uma conduta separada, mas uma atividade inerente à dinâmica do ser vivo; definido como 'científico' por aplicar procedimentos condizentes com a conduta 'científica'. O ato da percepção e apreensão não pode ser desvinculado da história, desenvolvimento e situação momentânea do organismo (individual-social), no caso, do sujeito pesquisador. As delimitações se tornam, assim, objetivas somente em relação ao juízo de determinado pesquisador, que detém, em si, uma realidade singular e legítima, e que pode muito bem ser aceita, ou não, pela comunidade científica - que por sua vez, passará, ou não a utilizá-la. Sua 'responsabilidade' pode assim ser associada tanto sobre as qualidades e embasamento de suas reflexões e modelizações, quanto ao esforço de entendimento, respeito e abertura numa predisposição para a comunicação com outras "leituras de realidade" dos outros indivíduos e grupos.

\subsection{A Paisagem como Sujeito-Dependente}

Nesta direção de destaque da subjetividade na reflexão científica, também ficou constatada no campo da Cibernética que uma máquina de Turing não poderia compartilhar os seus processamentos internos de informação com outra máquina. Ou seja, houve a demonstração de que uma máquina não poderia 'interpretar' objetivamente o comportamento de outra máquina de Turing, em vista, de seus processamentos acontecerem de maneira interna, em outro domínio de funcionamento do domínio comportamental da outra máquina, e cujas condutas emergenciais resultantes não são, então, acessíveis ao domínio de processamento interno da primeira. Nestes termos de se considerar a máquina como uma analogia ao funcionamento do sistema biológico, pode-se considerar esse domínio comportamental como presente tanto na máquina instrumento-calculadora (Maquina de Turing), quanto nas máquinas biológicas, incluindo os humanos, Extrapolado para as proposições de uma teoria da observação Foerster (1978, p.139) lança a tese de que "nada é, ou pode ser, comunicado", isso por que a atividade de um sistema nervoso de qualquer organismo, enquanto fechado operacionalmente, não poder ser compartilhada com outro organismo. Ou seja, da mesma forma que na comunicação de duas máquinas de Turing, no ser humano os "processamentos neurais" acontecem de maneira interna ao corpo do indivíduoorganismo, em outro domínio de funcionamento do domínio comportamental do outro indivíduo no qual está se comunicando, e cujos comportamentos resultantes não são, por sua vez, acessíveis ao domínio de processamento interno do primeiro indivíduo - justificando a máxima "nada é, ou pode ser, comunicado", pois a comunicação entre dois indivíduos baseia-se em interpretações e não em comunicações objetivas. 
Esse fechamento operacional (neural) não quer dizer que as construções cognitivas dos indivíduos são isoladas das construções sociais ao qual a sua individualidade é referenciada e consolidada - uma vez que a individualidade humana é social. As proposições do indivíduo carrega, ao mesmo tempo, influências do eu, do outro, e do grupo. A comunicação, no caso humana, via linguagem, torna-se, portanto, referente à interpretação feita por um observador da interação de dois organismos, constituindo-se de uma representação interna de uma relação entre o eu e um outro. O que as pessoas, veem, são assim, construções conjuntas sobre um ambiente, com significados consensuais e dissensuais, mas que são, sob este filtro social, representações internas singulares aos indivíduos. Tuan (1980) já trazia considerações convergentes à variedade de percepção revelando as congruências, destacadas por Mingers (1995), entre Biologia do Conhecer e o campo humanístico:

A superfície da terra é extremamente variada. Mesmo um conhecimento casual com sua geografia física e a abundância de formas de vida, muito nos dizem. Mas são mais variadas as maneiras como as pessoas percebem e avaliam essa superfície. Duas pessoas não vêem a mesma realidade. Nem dois grupos sociais fazem exatamente a mesma avaliação do meio ambiente. A própria visão científica está ligada à cultura uma possível perspectiva entre muitas (TUAN, 1980).

Considerar a presença da subjetividade individual no discurso científico, embora motivo de discussão desde a Antiguidade, na ciência neopositivista e pragmática do pós Segunda Guerra Mundial foi preterida como meta, se revertendo na busca por uma descrição objetivista (por ex. no estudo da Paisagem) - e que as abordagens humanistas vieram questionar a partir das décadas de 60 e 70 . A perspectiva sistêmica complexa aqui demonstrada vêm em direção convergente ao realce da subjetividade das abordagens humanistas, ao destacar o fundamento representativo e interpretativo do conhecimento. Nesta direção, o ambiente em que um organismo vive(o homo sapiens, por exemplo) não contém informação alguma por si só, de forma que, o ambiente é tal como é (FOERSTER, 1978). Como já destacado Foerster (1978) faz tal afirmação a partir do pressuposto da Teoria da Informação de C. Shannon e W. Weaver, no qual a informação não é vista como um objeto discreto presente no ambiente, mas sim como uma emergência, uma totalidade, produto das relações entre entidades. Assim, isento de informações em si, este ambiente tornar-se-ia informação como resultado das operações de computação do sujeito que 'produz' objetos cuja classificação decorre do fato de se aplicar a cada um deles um rótulo, ou nome invariante, em relação ao seu discernimento em um lugar no espaço e seu 'acontecimento' num determinado tempo. Nesta perspectiva, concebe-se que os objetos e acontecimentos do ambiente não detêm nenhuma realidade objetiva, isto é, não existem fora do organismo biológico, e, no nosso caso, independente das representações do sujeito pensante. $\mathrm{O}$ ambiente deve, assim sua existência às propriedades de representações, realizadas internamente à computação do sistema nervoso de algum organismo (BÉJIN, 1978, p.127, FOERSTER, 1978, p.139).

Para deixar claro, é óbvio que existe um mundo que é anterior a espécie homo sapiens, mas em termos de conhecimento, não podemos acessá-lo; aprofundando em termos científicos atuais os limites do conhecimento na experiência - destacado desde Kant (1989). Na verdade esse problema relativo à representação, no entremeio da relação sujeito e objeto, pode ser remetido às reflexões de constituição do pensamento ocidental moderno (ciência, filosofia, arte, literatura). Foi justamente a consciência da dúvida, de que "os sentidos nos enganam", e de que a representação do real não correspondia a uma cópia exata dele, que trouxe os problemas que originaram a filosofia e ciência modernas - no caso, como a razão poderia guiar a construção de um conhecimento rigoroso partir da representação. $O$ sujeito naquela ocasião detinha a certeza de que esta razão ofereceria o apoio necessário para se ter acesso e conhecer a realidade externa de forma objetiva, tal como ela se apresentava, primeiro em si (no século XVII e XVIII) e depois a partir da experiência (com Kant no final do XVIII). Nos dias atuais os diversos questionamentos àquela racionalidade (NOVAES, 1995), coloca novamente a representação em destaque na contemporaneidade. A noção de informação carregada pela Biologia do Conhecer traz uma noção de coisa em si ao qual não temos acesso, com a representação do ambiente sendo construído na relação do sistema biológico consigo mesmo e com o ambiente.

Dessa forma, a noção de informação pode ser considerada como uma noção cognitiva que remete tanto à incerteza do observador quanto ao sistema, situação ou fenômeno que esteja sendo considerado. Não se refere, assim, a uma noção que remeta a grandezas físicas, mesmo que uma descrição matemática tenha sido realizada (MATURANA, 1978, p.151). Assim, quando se fala, por exemplo, de 'processos erosivos' é normal que algum ouvinte interprete o sentido objetivo que a frase carregue, porém, constitui um erro tratar de processos erosivos como algo externo à representação ao qual está submetido. O movimento se dá ao contrário, o da representação em direção à 'objetividade entre parênteses' de incorporar a subjetividade como inerente; e não da objetividade, de pretender construir um conhecimento que exclua as subjetividades e refira-se da realidade em si.

A resistência e necessidade de incorporação da subjetividade nas leituras científicas da Paisagem pode ser visto quando Frolova (2007) coloca que: 
(...) Os cientistas, tentados pela investigação da objetividade na organização da paisagem, hesitam sobre a noção de paisagem de qualquer ordem sentimental e subjetiva. Essa tentativa será traduzida na Rússia por uma cisão semântica entre os termos paysage e Landschaft (FROLOVA, 2007, p.166). (...) . Os novos trabalhos russos consagrados à percepção das paisagens apresentam-se como ensaios de avaliação das qualidades estéticas das paisagens "utilizadas" para o lazer (que os geógrafos russos chamam de "Landschaften recreativos"). Propõem sistemas variados de índices qualitativos e quantitativos, evocados para objetivar a análise do processo subjetivo da percepção (FROLOVA, 2007, p.168).

Sobre isso Bertrand (2002), tanto releva o caráter biofisiológico, sócio-psíquico e singular ao indivíduo na construção da imagem da Paisagem, quanto não deixa de conceber o caráter objetivo, no sentido de objetividade típica, que ela carrega:

A paisagem é um objeto socializado, uma imagem, que só existe através do fenômeno fisiológico da percepção e de uma interpretação sociopsicológica. Aqueles que lidam com a floresta e os pastores vivem duas imagens diferentes, senão contraditórias, da mesma floresta (...). A paisagem nem por isso deixa de ser uma estrutura natural, concreta e "objetiva", isto é, independente do observador. A floresta é um espaço concreto e uma biomassa que funciona por si mesma (BERTRAND, 2002, p. 218).

É justamente a 'independência do observador' que a Teoria do Observador veio interpretar como uma falácia; e isso relevando as repercussões sistêmico-biológicas. Assim, mesmo que uma realidade externa e independente da percepção de um indivíduo seja aceita, a própria computo-cogitação envolvida nesta concepção, impede que qualquer conhecimento (epistemológico) a ser proposto acerca desta realidade passe como desprovida de qualquer influência de algum observador. Tais entendimentos questionam, portanto, o anseio da objetividade científica que almeja conhecer a realidade "em si", destituída de qualquer influência subjetiva. Como diria Bachelard (1977), nesta situação, a objetivação prevalece sobre a objetividade, no sentido que determinar um caráter objetivo não mais significa a exata coincidência entre o pensamento e o mundo, livre das subjetividades vacilantes, mas sim um esforço de objetivação sempre aproximada, onde razão e experiência não se dissociam. Com isso, determinar um caráter objetivo não mais significa ler uma realidade em-si a partir de fundamentos puros e absolutos, mas sim provar que se pode aplicar corretamente um método que já deu provas de seu valor lógico, mas que, contudo, não deixa de ser uma criação do espírito humano (BACHELARD, 1977, p.31-36).

Frente a esse contexto, um dos principais problemas de origem da ciência moderna, sobre a veracidade das coisas captadas pelo pensamento, fica pela Biologia do Conhecer respondido em duas vias de um mesmo processo. Por um lado, o sistema nervoso como um subsistema do organismo oferece um mecanismo eficiente de leitura do ambiente externo. Isso é o que chamamos de percepção, ou seja, uma objetivação do mundo externo a partir da configuração do sistema nervoso. Mas, por outro lado, fica impossível a esse sistema nervoso, enquanto sistema fechado operacionalmente, distinguir em seu funcionamento entre o que é percepção, ilusão e alucinação. Ou seja, os objetos que o organismo está vendo realmente estão lá no ambiente? Para o sistema nervoso enquanto um sistema operacional que funciona de forma cega (como o coração, o intestino, fígado etc) não é possível ter essa certeza. Quem distingue isso é um outro observador sobre a conduta daquele organismo, ou seja, se seu comportamento resulta das perturbações do ambiente (sendo assim uma percepção), ou se resulta de um funcionamento anômalo do sistema nervoso interno ao organismo (sendo uma ilusão). Considerando que o próprio observador está sujeito à mesma situação é a partir da linguagem, da construção conjunta e social de significados e das conversações que construímos socialmente, em grupo, a possibilidade de se referir a uma realidade em-si como externa ao sujeito - e daí reafirmar a possibilidade de externação da consciência de si do sujeito para uma realidade fora dele. Contudo, essa externação, pela Biologia do Conhecer, nunca será pura nos termos pretendidos pela objetividade tradicional neopositivista, pois sempre passará pelos filtros advindo dos processos autopoiéticos do ser vivo, que incluem sistemas fisiológicos, sociais e culturais. A noção de realidade torna-se, assim, sujeito-dependente, de forma que, nos dizeres de Maturana (1978), como as células nervosas desempenham o papel de filtros da realidade, não é possível chegar à conclusão de que existe algum traço de objetividade do mundo exterior a partir das configurações destas células; com essa própria proposição carregando retroativamente a objetivação advindo da linguagem, pelos consensos e dissensos, da cultura científica - tal como posto em Bachelard (1977).Essas considerações convergem com as discussões de Gröning (2004, p.10) que questiona o caráter verídico da Paisagem - tendência difundida pelos conservadores na Alemanha no pós-guerra. Ao buscar demonstrar a inerência de uma intencionalidade social e ideológica na reflexão e uso da Paisagem discorre: 
O homem é o único ser que formula leis naturais, às vezes as revisa, divulga-as nas escolas, reflete e discute sobre elas, revoga-as por razões religiosas, ou seja, culturais e, passados muitos séculos, volta a aceita-las.

(...) Leis da natureza sobrevivem apenas enquanto houver homens procurando entrar em acordo sobre elas, ou seja, tentando estabelecer uma relação com elas. (...) Enquanto "paisagem" não expresse também os interesses dos muitos e variados grupos sociais, o conceito me parece ser bastante questionável (GRÖNING, 2004, p.10).

Contudo, a discussão sobre os sentidos do caráter representacional e da sujeito-dependência da Paisagem não é nova. É uma reflexão estruturada desde séculos XVII e XVIII no quando da discussão sobre o papel da sensibilidade no conhecimento da natureza; e que repercutiu na formulação do conceito moderno de Paisagem que depois foi utilizado na Geografia:

O conceito de espacialidade e de paisagem na Geografia operacionalizam a noção de mundaneidade do mundo e ao mesmo tempo permitem uma ordenação da superfície da Terra e a criação do conceito de mundo. Esses conceitos tiveram sua origem no século XVII com o desenvolvimento da noção de sensibilidade, ou seja, a descoberta que além do corpo material havia algo mais, que movia o interesse das pessoas no mundo. (...) a sensibilidade deveria ser considerada na análise da realidade, pois a mesma seria a capacidade de uma pessoa em receber as percepções dos objetos externos, que seria causada pelo sentimento (VITTE, 2010).

Contudo, a partir de meados século XIX, com a estruturação e sistematização da Ciência promovida pelo positivismo, essas direções foram preteridas para o conhecimento científico. Tal sentido de representação, de sensibilidade estética pautada no sentimento, na emoção, foi deixada de lado a favor do procedimento racional com base no naturalismo científico - com os conhecimentos devendo se ajustar aos métodos das ciências naturais. Mas foi justamente no âmbito desta ciência de base naturalista que os limites daquela visão decimônica foram reconhecidos ao longo do séc. XX. Atualmente, sob bases sistêmico-biológicas, a sensibilidade foi resgatada, carregando consigo o caráter representacional do conhecimento (ATLAN, 1978).

Por serem membros de uma mesma espécie biológica, os homens compartilham de um mesmo e determinado padrão de organização genética, detendo uma mesma arquitetura nervosa. Esta estruturação biológica comum constitui o fundamento biológico de toda a sua unidade cultural, que, por sua vez, ao surgir socialmente, permite retroativamente coesões mais robustas e eficientes à preservação biológica dos indivíduos e do grupo - inclusive para construir significações e representações sobre o ambiente, bem como falar sobre ele. Neste movimento, as diferenças culturais e as histórias singulares dos indivíduos representam, em diferentes escalas, modos singulares de tratamento da realidade. Cada domínio cognitivo torna-se, assim, distinto, mas, igualmente legítimo. Por estes termos as diferenças culturais não representam modos diferentes de tratamento de uma mesma realidade objetiva, mas, principalmente, de domínios cognitivos distintos (e igualmente legítimos). Pode-se, portanto, dizer que as pessoas de culturas diferentes vivem em realidades cognitivas diferentes, e mesmo indivíduos de uma mesma cultura detém, no âmbito de sua ontogenia, sua própria singularidade de manifestação, sua própria história (determinação estrutural).

Nesta situação de questionamento da objetividade, os caráteres sócio-individuais e históricos se destacam na percepção da paisagem. Sobre os aspectos sócio-individuais pode-se dizer que, pelo sentido de objetividade tradicional, a Paisagem mesmo envolvendo desde sempre a presença do olhar, buscava refletir uma pretensa realidade objetiva, que, mesmo captada por um sujeito, conseguiria pela aplicação do método científico neopositivista encontrar uma possível verdade encoberta (como era o caso das leis científicas). Pela objetividade entre parênteses não há possibilidade, em termos epistemológicos de se conceber algo funcionando independente do observador e de toda a sua carga sensível e sócio-cultural. Em termos ontológicos pode-se, sim, conceber tal realidade, mas o seu conhecimento está inevitavelmente vinculado às determinações biológicas e sócio-cultural dos indivíduos/grupos. Trata-se portanto de tanto questionar a "objetividade" da objetividade, pelo filtro fisiológico-biológico (em direção à objetivação de Bachelard, 1977), quanto de demonstrar que a chamada objetividade científica também é uma construção social, com movimentos dialéticos envolvendo afirmação e contestação ao longo da história do conhecimento. É, portanto, possível conceber a realidade em-si, mas não conhecer o em-si da realidade. O observador, com suas cargas sensíveis, é assim, sempre objeto do conhecimento e auto-conhecimento, da epistemologia do conhecimento e do próprio observador. Essas objetivações, como já foi exposto, é o que a Biologia do Conhecer chama de "o observador se observar observando", com as próprias proposições (ontológicas e epistemológicas) do observador sendo elas próprias objeto do conhecimento e auto-conhecimento.

Sob referências próximas, tais argumentos já foram usados na reflexão da Paisagem: 
(...) a análise das representações das paisagens reintroduz o indivíduo, e sua sensibilidade, no processo social. O alargamento do campo geográfico para o biológico e o cultural devolve então, na natureza, todo o lugar ao indivíduo e ao individual (BERTRAND, 2002, p. 122).

De forma ambígua em relação à realidade 'independente do observador', já citada acima, Bertrand (2002), em momento mais recente de sua carreira, também realçou o fundamento subjetivo como inescapável:

(...) a paisagem não é um objeto "objetivo" suscetível de ser apreendido diretamente enquanto tal. Trata-se, com efeito, de uma porção de espaço delimitado por um olhar, assim posta em perspectiva e percebida por um observador através de uma filtragem de valores sociais, econômicos, religiosos, estéticos. A paisagem é então, desde a origem, um produto socializado e (...) a paisagem não é o registro neutro de fenômenos naturais (BERTRAND, 2002, p. 172).

Sob o viés dos sistemas complexos, pela Biologia do Conhecer, a presença da subjetividade na apreensão da Paisagem não significa torná-la menos objetiva - apenas se considerarmos o conceito de objetivo no âmbito da objetivação (BACHELARD, 1977) e não da objetividade. Nestes termos, relevando a carga sóciocultural que carrega, o sujeito (sistêmico-biológico) busca auto-objetivar-se para apreender, pela aplicação de um método, a Paisagem da forma mais adequada. Mas essa apreensão não está livre das "deformações" causadas pelas leituras singulares e em transformação dos diferentes indivíduos-observadores. A direção continua, assim, sendo a de buscar ultrapassar a aparência da apreensão superficial para uma apreensão rigorosa da Paisagem. Neste sentido, Gröning (2007), considera também que:

A percepção é sempre um processo seletivo de apreensão. Se a realidade é apenas uma, cada pessoa a vê de forma diferenciada; dessa forma, a visão pelo homem das coisas materiais é sempre deformada. Nossa tarefa é a de ultrapassar a paisagem como aspecto, para chegar ao seu significado. A percepção não é ainda o conhecimento, que depende de sua interpretação e esta será tanto mais válida quanto mais limitarmos o risco de tomar por verdadeiro o que é só aparência.

Tais entendimentos não são óbvios para a perspectiva científica de base neopositivista. Gröning (2007), por exemplo, é pesquisador na área da "Cultura do Jardim e Desenvolvimento de Espaços Livres" no campo da história e teoria de design relevando os aspectos sociais, econômicos e políticos do desenvolvimento humano para o planejamento da paisagem (NUCCI, 2007). Suas discussões sobre a paisagem não se baseiam numa leitura sistêmica da realidade, e sim humanista, associando questões ambientais com a percepção e vivência dos indivíduos. Há, assim, congruências já observáveis entre uma concepção humanística e a percepção da paisagem pelos sistemas complexos. Para uma abordagem dialética, por exemplo, a ideia de leitura "deformada" da realidade de Groning (2007) pode ser visto como inerente ao processo de transformação contraditória da realidade e do conhecimento - típicos dessa abordagem. Mas para a perspectiva científica, a busca tradicional sempre foi principalmente a da estabilidade, ordem e regra da natureza (exposto na ideia de lei científica). A inerência da transformação, do aleatório, do caos, da incerteza e do subjetivo na natureza e no fazer científico de base experimental é uma conquista recente cujas repercussões ainda são incipientes (PRIGOGINE e STENGERS, 1991) - com a Biologia do Conhecer fazendo parte desse movimento chamado de Complexidade. Pela leitura realizada, sendo o ser vivo (e o sujeito observador) um sistema autopoiético (sistema complexo) em ininterrupta interação e transformação com o ambiente (ontogenia), a apreensão da Paisagem se torna um movimento constante de produção de uma percepção no qual o sujeito, ao mesmo tempo, num mesmo processo, se forma como sujeito simbólico e constrói significados pela apreensão do ambiente, envolvendo a paisagem - sendo, assim, constituinte e constituído por esta percepção que inclui a apreensão da paisagem.

Sobre o caráter histórico da apreensão da Paisagem, pode-se dizer que esta fica determinada estruturalmente às condições do organismo indivíduo-social no instante da percepção e reflexão da Paisagem - dependente de sua ontogenia. Numa tonalidade de transformação, tal qual Heráclito, as ininterruptas mudanças estruturais característica de todo organismo biológico tornam a percepção e apreensão da Paisagem dependente das condições do organismo do pesquisador (ao mesmo tempo individual e social). E isso tanto em termos da história de sua deriva estrutural individual e social (no sentido de quanto arcabouço o sujeito adquiriu, em sua história, sobre o tema que está estudando), quanto em termos momentâneos, com a Paisagem sendo uma apreensão efêmera, variantes, ao longo do dia, da visada, dos focos específicos escolhidos pelo organismo-sujeito a cada instante (e que envolve aspectos biológicos, sociais e culturais). 
Como, então, neste movimento de variação e efemeridade da percepção encontrar algo de comum e universal entre o que dois indivíduos e grupos sócio-culturais distintos chamam de paisagem? E que determine que, independente das diferenças de leituras, ambas sejam consideradas paisagem? Existe, por esta perspectiva, um "ser da paisagem" independente da cultura e da apreensão do sujeito? visto agora como um sistema complexo? Primeiramente, se indivíduos estiverem inseridos em diferentes culturas sem nenhuma correspondência simbólica, tal como Europeus e os povos nativos das Américas no final do século XV, serão incertas quais similaridades poderiam ser encontradas entre o que ambas culturas consideram como paisagem, uma vez que, a produção de referências simbólicas e do conhecimento, conforme discutido, não é apartada das condições bioantroposocial, tal como defende Morin (1999). Sendo assim, é incerto (e exigiria pesquisa) o quanto há de similaridade e diferença entre tais concepções. Por outro lado, para uma mesma cultura, com tradições e princípios sociais e de conhecimento comuns, são os consensos e dissensos discutidos pelos grupos quem definirão os métodos e padrões perseguidos. Contudo, não podemos dizer que exista um "ser da paisagem" independente da cultura e da apreensão do sujeito-observador - como um sistema complexo. $\mathrm{O}$ em-si da Paisagem é, assim, uma referência usada para o processo de objetivação da apreensão, mas não algo que possa ser alcançado enquanto meta.

Tais entendimentos ajudam a melhor fundamentar alguns argumentos sistêmicos já elaborados sobre a Paisagem, por exemplo em Bertrand (2002):

Cada um tem seu lugar e seu papel em função de sua cultura, de suas percepções e, sobretudo, de seus projetos paisagísticos [...] um mesmo indivíduo (ou uma mesma categoria social) pode ter, em circunstâncias diferentes, atitudes diametralmente opostas a respeito de uma mesma paisagem (BERTRAND, 2002, p. 336). Um pinheiral é ao mesmo tempo um ecossistema, uma paisagem, uma massa de produção de matéria fibrosa, um espaço de caça etc., para atores diferentes ou mesmo para um único e mesmo ator (BERTRAND, 2002, p. 208). (...) a análise das representações das paisagens reintroduz o indivíduo, e sua sensibilidade, no processo social. O alargamento do campo geográfico para o biológico e o cultural devolve então, na natureza, todo o lugar ao indivíduo e ao individual (BERTRAND, 2002, p. 122).

O contexto da Complexidade veio, então, justamente fundamentar nas "ciências analíticas" tais considerações de Bertrand (2002) - oferecendo novos elementos para aprofundarmos a discussão. Por um lado, o pinheiral, por exemplo, não pode ser considerado um 'pinheiral' em-si, externo à representação do sujeito - sua própria delimitação física é uma abstração na gama de interações complexas nos sistemas ambientais, com a morfologia (do pinheiral) por si só não definindo a gama de relações envolvidas. Assim como é uma abstração afirmar que exista algo como um pinheiral em-si, que exista independente da percepção individual-social do sujeitoobservador. As definições responderão sempre à definição do método de percepção do sujeito-observador - com este devendo sempre se auto-objetivar sobre as limitações da abordagens e procedimentos aplicados. Por outro lado, a análise das representações das paisagens destacadas por Bertrand (2002) são posteriores ao processo autopoiético de auto-produção do sujeito enquanto ser vivo. Assim, a reintrodução do indivíduo, e sua sensibilidade, são inerentes aos processos de representação e criação da paisagem, não como um objeto em-si, mas sim como uma realidade sujeito-dependente, ao mesmo tempo construído individual e socialmente.

A Paisagem percebida pelo Sujeito (enquanto um sistema complexo) varia assim, de acordo com a história de interações sociais e culturais do pesquisador e é limitada à sua própria fisiologia individual no instante da apreensão - determinado estruturalmente por seu organismo. A Paisagem captada não se refere a algo externo ao sujeito, mas a algo interno a ele, de como este sistema complexo 'olhou' e representou o mundo a partir de suas possibilidades biológicas, sociais e aplicando um método. E este método que era tratado como algo que guiaria racionalmente a descrição verídica do mundo se tornou uma criação humana, que é consensualmente afirmada pelos seus membros pela aplicação comum de seus princípios e condutas (sistêmico, dialético, hermenêutico etc). Longe de independente do observador a apreensão da Paisagem se torna então arbitrária, enviesada e efêmera; ou seja, se torna múltipla e dinâmica em termos epistemológicos. Tais considerações não são estranhas às Humanidades, mas no âmbito das ciências analíticas isso é novo.

\section{Considerações Finais}

A apreensão da Paisagem é, em seu sentido e prática fundamental, sujeito-dependente. Esse pode ser um argumento que as abordagens humanísticas podem corroborar sem maiores problemas. E o campo científico parece estar se direcionando justamente para o encontro das humanidades, em sua base existencial e prática. 
Pela leitura realizada do sujeito pela Complexidade a ciência analítica, em seu sentido tradicional (sob referência da lógica e matemática), não é, portanto, um campo objetivo que consiga conhecer o em-si da realidade, independente do sujeito do conhecimento tal como previa a objetividade nos moldes neopositivistas. A ciência é sim um campo de conhecimento dependente do sujeito e definido por uma metodologia que especifica as propriedades que guiarão este sujeito do conhecimento. A metodologia e a destreza do sujeito é quem guiará a objetivação (e não objetividade) das reflexões e práticas da pesquisa. Dessa forma, as questões epistemológicas que surgem do próprio desenvolver cultural unificado, que constitui o campo científico, demonstram a carência do substrato da existência de um sujeito racional capaz de conhecer objetivamente a realidade. Não é, assim, possível afirmar nenhuma asserção objetiva acerca desse substrato, pois qualquer asserção referente a ele, ocorrerá sempre dentro do domínio cognitivo que é dependente de um sujeito - com essa própria proposição carregando, retroativamente, o caráter representativo individual e socialmente construído. As verdades científicas tornam-se referente aos domínios de coerências operacionais ao qual estão referenciadas, podendo ser admitido a existência de múltiplas versões da realidade, não mais referente à realidade em si, mas sobre a experiência de um sujeito e grupo. As verdades deixam de falar do mundo 'tal como ele existe' para passar a referir-se a espaços consensuais. A Paisagem bem expressa tal sentido.

A Paisagem se torna ao mesmo tempo individual e social, pois não separa a ideologia do sujeito (que é socialmente construída) da sua individualidade autônoma - e isso em termos biológicos. Contudo, a paisagem torna-se dependente das condições singulares do organismo (sujeito) que observa, no momento que observa, variando de acordo com as condições do organismo em sua relação com o ambiente (que também é variante).

Com isso, a paisagem se torna momentânea, efêmera, vacilante, em vista da característica do organismo que a apreende ser justamente um processo em transformação, com a leitura da paisagem variando de acordo com essa transformação que é ininterrupta. Isso, é claro, não quer dizer uma variação esquizofrênica de olhares e interpretações, mas sim, uma apreensão que varia de acordo com o indivíduo, e num mesmo indivíduo, dependendo de sua história, das intencionalidades da pesquisa, e das condições do organismo no momento da percepção. Não há assim, perspectiva privilegiada e objetiva de captação da paisagem. Percebida por um sistema complexo a paisagem é interna, por isso, cabe perguntar para as pessoas e grupos o que ela significa.

\section{Referências}

ATLAN, H. Consciência e Desejo em Sistemas Auto-organizados. MORIN, R. PIATTELLI-PALMARINI, M., BÉJIN, A. A unidade do homem: invariantes biológicos e universais culturais. Vol. II. São Paulo: Cultrix : Ed. USP, 1978, p176-193.

BACHELARD, G. Epistemologia. Rio de Janeiro : Zahar editores, 1977.

BÉJIN, A. Teoria da cognição e epistemologia da observação. In: MORIN, E. PIATTELLI-PALMARINI, M (Orgs). A unidade do Homem. Vol. II. São Paulo : Cultrix : ed. USP, 1978, p.126-129.

BERTALANFFY, L. V. Teoria Geral dos Sistemas. Petrópolis : Editora Vozes, 1973, 351p.

BERTRAND, C. BERTRAND, G. Uma Geografia Transversal - e de travessias - O meio ambiente através dos territórios e das temporalidades. Maringá: Ed. Massoni, 2002.

DESCARTES, R. O mundo ou Tratado da luz e O homem. Campinas: Unicamp, 2009.

DUPUY, J. Nas origens das ciências cognitivas. São Paulo : Edit da Univer. Paulista, 1996.

DUTRA GOMES, R. Ontologia Sistêmica: construção do espaço e perspectiva ambiental. GEOUSP, 25, p.109-122, 2009.

DUTRA-GOMES, R. Geografia e Complexidade: das diferenciações de áreas à Nova Cognição do Sistema Terra-Mundo. Tese de Doutorado, Instituto de Geociências, UNICAMP/Campinas, 2010.

DUTRA-GOMES, Rodrigo; VITTE, Antonio Carlos. Geografia: sobre sua unidade e fragmentação. Revista Terra Livre, v. v.2, p. 121-149, 2012.

DUTRA-GOMES, Rodrigo; VITTE, Antonio Carlos . O Geossistema pela Complexidade: Uma releitura das Esferas Geográficas. Revista do Departamento de Geografia, v. 35, p. 15-27, 2018.

ENGELS, F. O papel do trabalho na transformação do macaco em homem. São Paulo : Editora global, 1990.

ESTEVEZ DE VASCONCEllos, M. J. Pensamento Sistêmico - o novo paradigma da ciência. Campinas : Papirus, 2002. 
FOERSTER, H. V. On self-organization systems and their environments. p.02-22. In: Observing systems. Seaside : Intersystems, 1984, 331p.

FREZZATTIM W, A. A superação da dualidade cultura/biologia na filosofia de Nietzsche. Tempo da Ciência, Vol. 11, 22 : p.115-135, 2004.

FROLOVA, M. A Paisagem dos geógrafos russos: a evolução do olhar geográfico entre os séculos XIX e XX. R. RA'E GA, Curitiba, n. 13, p. 159-170, 2007.

FOERSTER, H. V. Notas para uma epistemologia dos objetos vivos. In: MORIN, E. PIATTELLIPALMARINI, M. A unidade do homem, Vol. II : invariantes biológicos e universais culturais. São Paulo: Cultrix : Ed. USP, 1978, p.132-146.

FOERSTER, H. V. On self-organization systems and their environments. In: Observing systems. Seaside: Intersystems, 1984, p.02-22..

GRACIANO, M. M. C. A teoria biológica de Humberto Maturana e sua repercussão filosófica. Dissertação de mestrado. Belo Horizonte: FAFICH / UFMG, 1997.

GRÖNING, G. A questionabilidade do conceito de paisagem. RA'E GA, Curitiba, n. 8, p.09-18, 2004.

HEISENBERG, W. Física e Filosofia. Brasília: Ed. Universidade de Brasília, 1981, 149p.

HEYLIGHEN, F. JOSLYN, C. Cybernetics and Second-Order Cybernetics. p.01-24. In: MEYERS, R. A. Encyclopedia of Physical Science \& Technology, New York : Academic Press, 2001.

KIRK, W. Problemas de la geografia. In: RANDLE, P. H. Teoria de la Geografia. (primeira e segunda parte). Buenos Aires : GAEA, Sociedad Argentina de estúdios geográficos, Série especial, №4, 1977, p.303330.

LA METTRIE, J. O. L'homme-machine. Paris: Folio, 1981.

LUZZI, R., VASCONCELLOS, A. R. Algumas considerações sobre a complexidade, auto-organização e informação. Campinas/SP.: IFGW / UNICAMP, 1999.

MATURANA, H. Estratégias Cognitivas. In: MORIN, E. PIATTELLI-PALMARINI, M. A unidade do Homem. Vol. II : invariantes biológicos e universais culturais. São Paulo: Cultrix: ed. USP, 1978, p.148170.

MATURANA, H. A ontologia da realidade. Belo Horizonte: ed. UFMG, 1997.

MATURANA, H. La objetividade: un argumento para obligar. Santiago, Chile: Dolmen Ediciones S.A., 1997.

MATURANA, H. VARELA, F. A árvore do conhecimento. São Paulo: P. Athenas, 2001.

MAYR, E. Isto é Biologia: a ciência do mundo vivo. São Paulo : Companhia das Letras, 2008, 428p.

MENDOZA, J. G., JIMÉNEZ, J. M., CANTERO, N. O. El pensamiento geográfico. Estudio interpretativo y atontogía de textos (De Humboldt a las tendencias radicales). Madri: Editoral Alianza, 1988, 545p.

MINGERS, J. Self-producing systems. Implications and Applications of Autopoiesis. New York: Plenun Press, 1995.

MORIN, E. O paradigma perdido: a natureza humana. 5. ed. Mem Martins: Europa. America, 1991.

MORIN, E. O método. Vol. 3 - O conhecimento do conhecimento. Porto Alegre : Sulina, 1999, 287p.

MORIN, E. A cabeça bem feita: repensar a reforma, reformar o pensamento. Rio de Janeiro: Bertrand Brasil, 2003.

MORIN, E; LE MOIGNE, J. A Inteligência da Complexidade. São Paulo: Petrópolis, 2000.

NOVAES, A. A Crise da Razão. São Paulo : Companhia das Letras, 1996, 563p

NUCCI, J. C. Apresentação da Conferência de Gert Gröning. Revista RÁE GA, Curitiba, n. 11, p. 141-142, 2008.

PRIGOGINE, I., STENGERS, I. A nova aliança. Brasília: Editora da UNB, 1991.

RAMOS, E. M. F. O trabalho de Humberto Maturana e Francisco Varela. s/p. Disponível em: http://www.inf.ufsc.br/ mariani/autopoiese/maturanaedla.html, Acesso em 03/04/2016.

SANTOS, M. Metamorfose do Espaço Habitado. São Paulo : Edit. Hucitec, 1988. 
SCHALL, B. Darwin e Marx, Durkheim e Weber: relações entre a forma de pensar evolução na biologia e na sociologia. Revista UFMG, Belo Horizonte, v. 21, n. 1 e 2, p. 138-149, jan./dez. 2014

STODDART, D. R. Darwin's Impact on Geography. Annals of the Association of American Geographers. Vol. 56, No 4, p. 683-698, 1966.

STRATHERN, Paul (1997). Einstein e a Relatividade. Rio de Janeiro: Jorge Zahar Editor, 1998.

VICENTE, L.E.; PEREZ FILHO, A. Abordagem Sistêmica e Geografia. Geografia. Rio Claro: v. 28, n. 3, p. 345-362, 2003.

VITTE, A. C. Da sensibilidade à representação da Paisagem: considerações sobre a estética da natureza como um recurso para sensibilização ambiental. RA'E GA, Curitiba, n. 20, p. 7-17, 2010. 